\title{
NUEVOS DATOS ACERCA DE LAS FOLLAS DE ENTREMESES DEL SIGLO DE ORO
}

\author{
CRistina RoldÁn FidAlgo \\ Universidad Autónoma de Madrid \\ cristina.roldanf@uam.es
}

\section{INTRODUCCIÓN}

U na de las manifestaciones del teatro del Siglo de Oro más desconocidas sigue siendo la denominada folla de entremeses, que aparece citada ocasionalmente en los estudios teatrales sin que se haya recopilado un número suficiente de fuentes como para poder caracterizarla. Tan solo se dispone de noticias aisladas que dan cuenta de su existencia, fundamentalmente debidas al trabajo de N. D. Shergold y J. E. Varey (1963: 212-244), y a la hora de exponer sus características, los estudiosos aún recurren a una de las acepciones del término «folla» que propuso Sebastián de Covarrubias en su Tesoro de la lengua castellana o española: «Los comediantes, cuando representan muchos entremeses juntos sin comedia ni representación grave, la llaman folla, y con razón, porque todo es locura, chacota y risa» (Covarrubias, 1611: 859).

El filólogo Eugenio Asensio señalaba que «nunca el género menor se hizo enteramente independiente y fue presentado aparte del mayor como no sea en las llamadas "follas de entremeses" que se representaban principalmente en los días de Carnaval» (1971: 16). Para ello se basaba en una acepción del término «folla» recogida por el Diccionario de autoridades (1732), muy similar a la del Tesoro, y en los datos proporcionados por Shergold y Varey que la vinculaban con dicha fiesta. Añadía en nota a pie de página: «estas "follas" eran representadas incluso ante la corte [...] De esta modalidad apenas si sabemos algo [...]» (1971: 16).

Emilio Cotarelo y Mori advertía en su Colección de entremeses, loas, jácaras y mojigangas que

Edad de Oro, XXXIX (2020), pp. 191-206, ISSN: 0212-0429 - ISSNe: 2605-3314

DOI: https://doi.org/10.15366/edadoro2020.39.010 
las follas no eran intermedios, sino clases o maneras de espectáculo [...] Pero a veces el mismo intermedio se componía de fragmentos de otros (entremeses, bailes, loas, jácaras, mojigangas) todo ello muy reducido y solo como pretexto para cantar, bailar, declamar o sonar en la orquesta, pasajes de los que habían sido más reídos y celebrados en las respectivas piezas que los contenían [...] (1911: 314).

Según el erudito asturiano, la folla sería un modo de espectáculo que consistía en reunir distintas piezas breves.

Tras dichas aportaciones, tan solo Luis Estepa ha avanzado en la investigación, aunque centrando el foco de estudio en las follas del siglo XVIII. En relación al objeto que aquí nos ocupa, afirmaba que la etiqueta de follas de entremeses «puede denotar tanto una manera de componer un espectáculo, como un grado de pérdida de uso de la palabra precisa que sirviera para designar un género dramático» (Estepa, 1991: 418), inclinándose por esta segunda opción. Defendía así que se trataba de un género por sí mismo y no de una modalidad de espectáculo, como se consideraba en los estudios anteriores y como defendiera también el filólogo Javier Huerta Calvo:

Más que una forma literaria diferenciable de las anteriores, la folla (de folía, «locura») era una modalidad de espectáculo, que podía agrupar un conjunto de piezas cortas representadas una tras otra en bulliciosa y frenética sucesión, sin la comedia [...] Disiento del criterio de Luis Estepa, para quien se trata de un verdadero género dramático [...] (2001: 80).

Como puede comprobarse, aún son numerosos los interrogantes en torno a la naturaleza de dichas follas y esto se debe en buena medida a la escasez de fuentes documentales conocidas que describan o informen sobre cómo se desarrollaban este tipo de espectáculos. En el presente trabajo se pretende aumentar el número de fuentes y contribuir de ese modo a un mejor conocimiento de las follas de entremeses. No se aspira a ofrecer un listado definitivo de las follas que se representaron en el Siglo de Oro, ya que se espera que este aumente en los próximos años con futuros estudios, pero sí significativo, debido a que, como queda dicho, hasta el momento apenas se conocían noticias aisladas gracias al trabajo de N. D. Shergold y J. E. Varey. Los autores de las inestimables Fuentes para la historia del teatro en España llevaron a cabo un vaciado del legajo 666 del Archivo del Palacio Nacional, es decir, el actual 11.744 del Archivo General de Palacio («Espectáculos públicos y privados»), dando a conocer la representación de algunas follas que se recogerán en este trabajo y a las que se añadirán otras procedentes de fuentes nuevas.

En primer lugar, se ha realizado una búsqueda del término «folla» en el Corpus Diacrónico del Español (CORDE), con el objetivo de determinar cuáles 
fueron los primeros textos en los que este se registra con un sentido teatral y, de este modo, conocer hasta qué año podría remontarse la existencia de dicho espectáculo. En segunda instancia, se documentan una serie de puestas en escena de follas de entremeses hasta el momento desconocidas, que tuvieron lugar en diversos espacios durante el Siglo de Oro. Con todo ello se pretende contribuir a paliar este vacío documental.

\section{REFERENCIAS EN LA LITERATURA}

En el capítulo II de la primera parte de la Vida del pícaro Guzmán de Alfarache (1599), de Mateo Alemán (1547-1615), encontramos lo que podría considerarse como una primera referencia a la folla. En el fragmento que se presenta a continuación, el autor pretende distinguir entre dos tipos de necesidad, para lo cual emplea una serie de metáforas. Entre ellas, se cita a la folla junto a géneros dramáticos como la farsa y la tragedia, lo que induce a pensar que el sentido al que se refiere aquí Mateo Alemán no es otro que el correspondiente a la folla como forma teatral:

Dos maneras hay de necesidad: una desvergonzada que se convida, viniendo sin ser llamada; otra que, siendo convidada, viene llamada y rogada. La que se convida, líbrenos Dios de ella [...] Es fuste en quien se arman todos los males, fabricadora de todas traiciones, fuerte de sufrir y de ser corregida, farol a quien siguen todos los engaños, fiesta de muchachos, folla de necios, farsa ridiculosa [sic.], fúnebre tragedia de honras y virtudes (Alemán, 1996: 239).

Dado que la primera parte de la novela picaresca fue publicada en 1599, esto indicaría que la folla era una forma dramática ya conocida a finales del siglo XVI.

En torno a ese año se escribió la comedia Argel fingido y renegado de amor de Lope de Vega (1562-1635). En su segundo acto aparece de nuevo la folla, citada entre una sarta de disparates que el personaje de Celio dice a Leonido. En esta ocasión, se hace manifiesta la vinculación de la folla con el entremés:

Llega la mañana pues, y no hay qué comer, ni olla, allí empieza el entremés, allí se traba la folla, y hablan guineo y francés

(vv. 1.405-1.409).

El verbo «trabar» podría haber sido empleado en su significado de «Juntar o unir una cosa con otra para mayor fuerza o resistencia» (Diccionario de 
autoridades, s.v.) en coherencia con la definición de Covarrubias, según la cual las follas enlazaban o «trababan» diversos entremeses.

La siguiente referencia aparece en el capítulo IX de otra novela picaresca, El Guitón Onofre, de Gregorio González, publicada en el año 1604. El texto da cuenta de las tres acepciones del término «folla» recogidas por Covarrubias:

Llegamos al tabladillo y, en viendo la camarada, como lo tienen de costumbre, comenzaron los vinateros a dar voces diciendo: « $\ll_{\mathrm{E} a}$, palomos! ¡Ea, colegiales! ¡Aquí está lo bueno, parroquianos! ¡Helo aquí lo bueno! ¡Helo aquí!». Vierais una folla de voces, como de entremeses, y de golpes en torneo de a pie (1995: 156).

En efecto, en el Tesoro se incluye no solo el significado de «folla» como conjunto de entremeses, sino también como parte final de los torneos y como algarabía:

Es propio de los torneos, que después de haber torneado cada uno por sí con el mantenedor, se dividen en dos cuadrillas, y unos contra otros se hieren tirando tajos $\mathrm{y}$ reveses sin orden ni concierto, que verdaderamente parecen los unos, y los otros, estar fuera de sí. Y por esto se llamó folla, quasi folia, id est, locura. A imitación de esto llamamos la folla el concurso de mucha gente, que sin orden ni concierto hablan todos o andan revueltos por alcanzar alguna cosa. Los comediantes, cuando representan muchos entremeses juntos sin comedia ni representación grave, la llaman folla, y con razón; porque todo es locura, chacota y risa (Covarrubias, 1611).

De modo que todo parece indicar que la folla de entremeses era un espectáculo que ya se desarrollaba en el siglo XVI, y era lo suficientemente conocido como para ser citado en obras literarias de finales de la centuria. No es asunto baladí, pues si solo se tuvieran en cuenta las noticias de su representación, no podría fecharse antes del siglo XVII.

\section{RePRESENTACIONES DE FOLLAS DE ENTREMESES}

Los testimonios que informan de la representación de follas en el Siglo de Oro fundamentalmente aportan información acerca de la fecha y el lugar de su representación, así como de lo que parece haber sido su composición, al distinguir entre follas «de entremeses» $\mathrm{y}$ «de bailes». Escasean, sin embargo, las descripciones de estos divertimentos.

La mayoría de estas follas parecen haber sido «particulares», es decir, funciones ofrecidas por las compañías de los corrales, pero no en el recinto teatral, sino en casas privadas o en palacio ante los monarcas. El Diccionario de autoridades en 1737 definiría un particular como «la comedia que se representa por los farsantes fuera del teatro público». Por lo general, solían ser piezas de repertorio (Shergold, 
1982: 14), por lo que no es aventurado suponer que las follas reunieran obras que se hubieran representado con anterioridad en los corrales. No obstante, se documenta un caso en el que la folla fue dispuesta por los ayudas de cámara del rey; y es que, en efecto, no sería imprescindible la intervención de cómicos, pudiendo cualquiera organizar una folla «de aficionados», surtida de distintas piezas.

Como anunciara Eugenio Asensio, en esta época las follas suelen formar parte de las diversiones de carnestolendas, vinculadas así al calendario festivo, pero la presente investigación demuestra que también se representaban con motivo de acontecimientos señalados, para agasajar a las visitas o, en el caso de la realeza, para festejar fechas importantes.

Se han documentado un total de ocho follas, con el foco de atención en aquellas que se pusieron en escena ante los monarcas en el Real Alcázar y en el Buen Retiro. De ellas dan cuenta algunos datos contables, derivados del pago a los autores de las compañías de los corrales, y relaciones históricas. También se recoge una folla que se interpretó en una casa privada de Salamanca por ser la primera representación que se ha podido documentar.

\subsection{En una casa privada de Salamanca (1604)}

La noticia más temprana de la representación de una folla que hemos conseguido documentar data del año 1604 y se encuentra dentro del diario del legista florentino Girolamo da Sommaia, conservado en la Biblioteca Nacional de Florencia y editado por George Haley en 1977. Durante su estancia como estudiante en Salamanca, Girolamo redactó una minuciosa crónica de su época. Sus escritos contienen una rica colección de datos para la historia del teatro en los primeros años del siglo XVII, registrando las compañías de cómicos que pasaban por la ciudad, los títulos o las descripciones de las comedias representadas, y hasta el día, mes y año de las representaciones (Da Sommaia, 2012: 26).

El 9 de enero de 1604 escribe: «Visitai Signor Salas. Fui a casa Don Rodrigo de Naruayez. Si uotò ${ }^{1}$. Represento [sic.] Porras folla de entremeses» (Da Sommaia, 2012: 138). Probablemente con «porras» se refiriese al autor de comedias José Gaspar de Porres, que, efectivamente, a veces aparecía como Porras (Shergold, 1982: 39; Allen, 1991: 337). Con el nombre de «autor de comedias» se designaba a la figura que ejercía como lo que ahora se conoce como director, y era además el responsable de la compañía (Díez Borque, 1978: 44).

Gaspar de Porres nació en Toledo en 1550. La primera noticia sobre su actividad teatral documenta la representación de tres autos sacramentales en Madrid, en las fiestas del Corpus de 1585. El 5 de marzo del mismo año firmó un conocido contrato con Miguel de Cervantes, en el que este se comprometía a entregarle dos

1 «Fue genial» (traducción propia). 
comedias, La confusa y El trato de Constantinopla y muerte de Selim. Antes del fin del siglo XVI, Porres representó distintas obras en Madrid, Valencia, Toledo, Sevilla y Lisboa. Fue jefe de una de las ocho compañías autorizadas por el Real Decreto de 26 de abril de 1603 (Sánchez Arjona, 1898: 79). Durante ese año, su compañía estuvo en Sevilla, pasando a Madrid en fechas cercanas a la representación de la folla y volviendo a Toledo en el mes de mayo de 1604 (Allen, 1991:340).

De modo que Gaspar de Porres habría acudido con su compañía a representar algunos de los entremeses de su repertorio para ofrecérselos al dueño de la casa, don Rodrigo, y a sus invitados, con motivo de la visita de Juan de Salas ${ }^{2}$. En esta época, la compañía contaba — además de con el propio Porres y su mujer, Catalina Hernández de Verdeseca - con Salvador de Ochoa; Sebastián Morales, que desde 1600 se turnaban en el papel de primer galán; Domingo Balbín y su mujer, Isabel de Berriz; Mariana Velasco, mujer del citado Salvador de Ochoa; Miguel Ruiz y su esposa, Baltasara de los Reyes; Pedro Cerezo de Guevara; Francisco de la Guardia y Diego de Vega (Haley, 1971: 260).

\subsection{En el Real Alcázar (1623-1636)}

La siguiente folla de la que se tiene noticia se fecha el 28 de febrero de 1623, un martes de carnestolendas, y tuvo lugar en el Salón Grande del Real Alcázar ante los reyes, Felipe IV e Isabel de Borbón. Es un caso excepcional, ya que a ella se dedicó una relación con el título Breve relación de la fiesta que se hizo a Sus Majestades y Altezas Martes de Carnestolendas en la noche en el Alcázar de Madrid en este año de 1623, conservada hoy en la Biblioteca Nacional de España ${ }^{3}$.

La relación comienza describiendo el lugar y a los asistentes:

Hízose esta fiesta en el salón grande que hay en el Real Alcázar para las fiestas públicas. Y estuvieron Sus Majestades y Altezas, damas, señoras y meninas en la forma y manera que suelen en las comedias ordinarias. Y porque toda ella fuese de los caballeros de cámara, de Su Majestad y del Serenísimo Infante Cardenal, de algunos grandes, y ayudas de cámara y mayordomos, fue orden de Su Majestad que ninguna persona entrase a verla sino tan solamente los señalados y puestos entrasen vestidos de máscara. Hízose así tanto que siendo necesarias algunas personas para el servicio, se mandó que todos entrasen vestidos sin excusar persona alguna (1623: f. 311r).

\footnotetext{
Con este nombre aparece en una entrada anterior del diario (Da Sommaia, 2012: 136).

3 Breve Relación de la fiesta que se hizo a sus majestades y altezas Martes de Carnestolendas en la noche en el Alcázar de Madrid en este año de 1623 (Biblioteca Nacional de España, ms. 2.354, ff. 311-312).
} 
El Salón Grande, Salón de Comedias o Salón Dorado — pues con todos estos nombres suele aparecer citado en la documentación - era uno de los recintos más representativos del Alcázar (Brown, 1985: 48). Ocupaba la planta principal del ala sur, la que correspondía a la fachada principal, por lo que sufrió varias reformas debido a las remodelaciones a las que fue sometido el edificio. Se sabe que hasta 1626 el Salón medía aproximadamente $165 \times 33$ pies castellanos ${ }^{4}$, pero fue sufriendo cambios y reformas durante el curso del siglo XVII (Flórez Asensio, 2006: 47).

La «forma y manera» en la que estuvieron los asistentes - como advierte el fragmento de la relación- debió ser la misma que se indicaba en las denominadas Etiquetas de Palacio, documento del que existen numerosas copias y que se modificó durante el transcurso del siglo XVII ${ }^{5}$. Así se da a entender cuando figura: «Y estuvieron Sus Majestades y Altezas, damas, señoras y meninas en la forma y manera que suelen en las comedias ordinarias». En cuanto a los actores, existen pocos datos que permitan vislumbrar la manera en que se escenificaban las funciones particulares. Se ha postulado que sus detalles escénicos serían similares a los de las representaciones realizadas en las cortes ducales y regias de principios del siglo XVI, esto es, con los actores al mismo nivel que los espectadores (Varey, 1984: 398-406). En todo caso, la representación de las follas no parece haber exigido escenografía, como sí lo hubiera hecho la puesta en escena de algunas comedias de espectáculo.

Prosigue el documento describiendo las distintas partes de la fiesta de 1623 y nombrando a quienes participaron en ellas. El festejo constó de numerosas danzas; hubo una comedia disparatada o burlesca, contando con el marqués de Velada $^{6}$ como autor; una boda teatralizada, que finalizaba con el juego de la sortija; y una folla de entremeses como intermedio. Esta fue la única de toda la fiesta que no era interpretada por los invitados al festejo, es decir, por marqueses y duques que hacían de intérpretes ocasionales, sino por compañías procedentes de los corrales.

4 El «pie castellano», también conocido como «pie de Burgos», es una antigua unidad de longitud.

5 Se consultó la copia siguiente: Etiquetas de Palacio, estilo y gobierno de la Casa Real que han de observar y guardar los criados de ella en el uso y ejercicio de sus oficios, desde mayordomo mayor y criados mayores hasta los demás criados inferiores. Funciones de la misma Casa Real ordenadas año de 1562 y reformadas el de 1624 años (Biblioteca Nacional de España, ms. 8.740, sin foliar; cit. en Vélez de Guevara, 1970: 68-69).

6 Se trataría de Gómez Dávila (c. 1535-1616), marqués de Velada. Fue mayordomo mayor de Felipe II, jefe de la casa y ayo del príncipe de Asturias, el que fue rey Felipe III. Era miembro del Consejo de Estado y del Consejo de Guerra, se le concedió el grado de grande de España y prestó grandes servicios durante el reinado de Felipe II; fue, asimismo, uno de los grandes nobles de la monarquía hispánica que logró la confianza de Felipe III. 
La descripción de la folla es como sigue:

En el inter[medio] que se previnieron las cuatro compañías de autores de comedias que al presente se hallaron en Madrid, entraron a representar diferentes y entretenidos entremeses y se los dio orden que el que mejor lo hiciese se le daría un premio y por no alargar tanto la fiesta, se acordó que la música de todas cuatro compañías cantase junta. Fue esto muy de ver y oír y lo fue más en acabando oír representar a todos los personajes de las compañías juntos y a un tiempo. Fue extraordinario pensamiento y esta confusión hizo grande novedad. Esto duró un buen rato. Dividiéronse las compañías y cada una hizo su entremés en que hubo muchas cosas de entretenimiento y risa. Acordose que acabados los entremeses se asentasen en forma de prado a la mano izquierda todas las farsantas [...] (1623: f. 312r).

Del testimonio se desprende, en primer lugar, que en la folla participaron las cuatro compañías que representaban por entonces en Madrid (la de Antonio García de Prado, la de Juan Bautista Valenciano, la de Manuel Álvarez de Vallejo y la de Pedro Valdés); y así lo verifican los datos que para ese año presenta el periódico El averiguador, de Cruzada Villaamil.

Según este, a García de Prado se le abonaron 600 reales en el mes de marzo de 1623 por dos comedias (El desengaño en celos y La camándula) y la folla de entremeses que hizo a su majestad los días 9, 23 y 28 de febrero (martes de carnestolendas) respectivamente. Al segundo la misma cantidad por tres particulares ofrecidos al monarca en esas mismas fechas: las comedias Siempre ayuda la verdad y El ayo de su hijo, y la folla de entremeses. A Vallejo, 900 reales por haber escrito cinco comedias para el rey, La venganza y el amor, La loca del cielo, Carlos en Túnez, El diablo predicador y la folla de entremeses (correspondiendo esta última al 28 de febrero). Por último, a Valdés se le abonaron 400 reales por la comedia Hacer bien sin saber a quién y la folla de entremeses (Cruzada Villaamil, 1871a: 8-9). Se infiere que la folla se pagaba como una comedia más, costando 200 reales, cantidad que era la habitual en la época ${ }^{7}$.

En segunda instancia, parece confirmarse que la folla estaba formada por entremeses. No obstante, al haberse ordenado que los músicos de las compañías cantasen juntos, cabe suponer que constaría asimismo de piezas musicales. Siguió a la folla un episodio de pretendida confusión en el que se habría mandado que todos los actores representasen sus papeles al mismo tiempo; esta interpretación coincide con la que expone John E. Varey en un artículo dedicado a todo el festejo (1971: 746).

Dos años más tarde, y esta vez no por carnaval, sino por los días de la reina Isabel de Borbón, se volvió a representar el 9 de julio de 1625 en el Real Alcázar una «folla

El pago oscilaba entre 200 y 300 reales por actuación. Un documento que trata de una serie de actuaciones ejecutadas en 1622-1623 informa de que «no se acostumbraba a pagar más de a 200 reales por cada comedia» (Shergold, 1982: 47-48). 
de bailes y entremeses». Recoge su representación Aureliano Fernández-Guerra y Orbe en su biografía de Francisco de Quevedo, que estuvo implicado en la escritura de la comedia a la que acompañó la folla. La fuente del historiador parecen haber sido los Avisos manuscritos de la Biblioteca Nacional de España. Dice así:

[Antonio Hurtado de] Mendoza [comendador de Zurita, de la Orden de Calatrava, secretario de la Cámara de Su Majestad y de la general Inquisición] pues, [Francisco de] Quevedo y Mateo Montero, criado del Almirante, solicitados por el marqués de Eliche y de Toral, yerno de Olivares, escribieron, para festejar los días de la reina Isabel de Borbón, una comedia llena de chistes muy donosos. Fue representada en el Real Alcázar el 9 de julio de 1625 por los ayudas de cámara, con la folla de bailes y entremeses, aderezo el más sabroso para la augusta familia (1859: 61).

Cabe destacar cómo en esta ocasión no fueron miembros de las compañías teatrales los que asistieron a palacio para representar la folla, sino los propios ayudas de cámara ${ }^{8}$, y que fue la folla un aderezo, es decir, un adorno del gusto de la familia real para complementar a la comedia. No se trataba, por tanto, de un particular, a diferencia de las anteriores y de las que se documentarán a continuación. Ciertamente, es normal que los testimonios localizados versen sobre las follas representadas por las compañías de los corrales, porque la mayoría corresponden a los pagos a sus autores. Pudieran haberse hecho muchas más follas a cargo del servicio del monarca, de cuya existencia no quedó un rastro contable.

Probablemente por este motivo hasta el año 1634 no se cuenta con nuevas noticias. El martes de carnestolendas de dicho año se representó una folla de entremeses, por la cual se pagó a Bartolomé Romero, siendo la folla uno de los cinco particulares que hizo a su majestad en el Salón (Cruzada Villaamil, 1871b: 107-108).

Romero fue cómico y autor de comedias. Estuvo en la compañía de Cristóbal de Avendaño en 1622-1623 y, al año siguiente, consta que se incorporó junto a su esposa, Antonia Manuela Catalán, a la compañía de Juan Bautista Valenciano durante solo un año. En 1626 compraron una casa en la calle madrileña de Santa María y, por entonces, Jacinto Cordero escribió para él El favor en la sentencia. Desde 1628, Romero figura como autor de comedias y no como intérprete, representando autos en Madrid, y en 1631 en Sevilla. En 1634 su compañía y las de Luis López y Pedro de Ortegón pusieron en escena autos en Sevilla, y antes debió haber estado en Madrid, cuando se interpretó la folla ante los monarcas. Sí consta que en 1636 representó cinco comedias de forma privada para el rey.

De la composición de su compañía solo se conoce la de 1637, esto es, tres años después de la fecha de la folla. La conformaban Mariana de los Reyes, Pedro

8 Según Covarrubias en su Tesoro de la lengua castellana (1611), los ayudas de cámara son «los gentiles-hombres que se dan por ayudas a los caballeros de la llave dorada, que son de la cámara de $\mathrm{S}[\mathrm{u}]$ $\mathrm{M}$ [ajestad] para que acudan a los ministerios ordinarios en que no se han de ocupar los señores». 
Valcázar y María de Valcázar, su mujer; Gabriel Cintor, Pedro García de Guevara, Tomás Enríquez, gracioso, Antonio Pinero, Onofre Pascual, Maximiliano Eustorquio de Morales, Juan Pérez y el galán Alonso de Osuna (Rennert, 1909: 582-583).

El martes de carnestolendas de 1636 se representó también en el Alcázar otra folla de entremeses, que fue abonada a la compañía de Juan Martínez de los Ríos junto a otras dos comedias, El alcaide de sí mismo (29 de enero) y El mejor amigo (2 de febrero), por 600 reales (Cruzada Villaamil, 1871b: 107).

Al igual que Romero, Martínez fue cómico y posteriormente autor. Junto a su esposa, Dionisia Suárez, estuvo en la compañía de Cristóbal Ortiz de Villazán en 1619-1620. Consta que fue autor de comedias desde 1623 hasta precisamente el año de representación de la folla, 1636. De sus representaciones ante el monarca, se documenta una del 11 de julio de 1633 y ocho comedias ante Felipe IV, en 1636, entre las que se hallaría la folla (Rennert, 1909: 519).

\subsection{En el Buen Retiro (1637-1653)}

En 1637 una folla formó parte de unos festejos que duraron al parecer desde el 16 hasta el 25 de febrero, siendo consideradas «las más grandiosas y variadas [fiestas] de cuantas vio la capital de la monarquía en tiempo de Felipe IV» (Memorial histórico español, 1862: 38). El motivo de estas celebraciones fue la coronación de Fernando III como rey de los Romanos (Sommer-Mathis, 2009: 65). La folla fue dispuesta por el conde duque de Olivares, por encargo de Felipe IV, y se representó en la ermita de la Magdalena. Olivares era la persona de confianza del monarca para organizar las fiestas teatrales de la corte. En sus planteamientos, el rey debía eregirse como punto focal de la vida artística y cultural de España (Ascunce, 2018: 16).

La mencionada ermita se situaba junto a la tapia norte del Retiro, delimitando el jardín con el camino de Alcalá, y había sido construida dos años antes. Estaba localizada con el número 89 en el denominado Plano de Teixeira (1656), el primer plano donde aparece el Real Sitio del Buen Retiro por completo. Sirvió

como pabellón de recepción de huéspedes ilustres que llegaban a Madrid por este camino, los cuales se podían ubicar en el pequeño volumen adosado a la ermita por su fachada sur. Por el otro lado de la tapia, en el interior del Retiro, la ermita servía también de telón de fondo de representaciones de comedias y otros festejos como mascaradas que tenían lugar en el amplio terreno que quedaba sin ningún tipo de vegetación colindante al muro (Ascunce, 2018: 16).

La folla se representó el segundo día, corriendo el primero a cargo de la condesa de Olivares con una fiesta en la ermita de San Bruno (otra de las ermitas situadas en los jardines del Buen Retiro) que constó de bailes, entremeses, danzas y una comedia de aficionados. Una relación coetánea titulada «De las fiestas que 
la Majestad Católica del Rey Nuestro Señor celebró en el Real Retiro a las felicísimas nuevas de la elección y coronación de Rey de Romanos en los Reyes de Hungría y Bohemia de diez días continuos, que comenzaron Domingo 16 hasta Martes 25 de Febrero» ofrece una descripción acerca de cómo se desarrolló el segundo día la fiesta que incluía la folla:

El Martes eligió Su Excelencia la Ermita de la Magdalena, túvola muy dispuesta, y con la sazón de entretenimiento que convenía a tan Soberanas Majestades, con una máscara de doce mujeres, muy diestras y bien prendidas, y recopilado en tres compañías cómicas, todo lo escogido de las habilidades, tramoyas, bailes, entremeses, y comedias de todo el año: folla tan del tiempo, que no tuvieron por perdido el que en verle gastaron los Reyes, y se remató la tarde con otra merienda que dio la misma Majestad igual a la pasada. Y por atención como del Conde diré que sobreviniendo un aire con el mismo (en la presteza) mudó todo el teatro, donde estuviese defendido de él, que pareció cosa de asombro («De las fiestas...», 1637: 20).

Cabe destacar que, por primera vez, en los testimonios localizados no se habla ya de folla de entremeses, sino de una folla que parece haber reunido «habilidades, tramoyas, bailes, entremeses, y comedias de todo el año» de tres compañías ( $s i n$ especificar de cuáles se trataba) $)^{9}$, como si se escogiera lo mejor que se hubiera visto en los corrales para ofrecérselo a los monarcas. Además, se advierte que la folla era propia del tiempo, es decir, propia del carnaval, como se daba a entender en las representaciones anteriormente documentadas aunque no se dijera de forma explícita como aquí.

Puede plantearse como hipótesis que las otras follas de entremeses mencionadas fueran de la misma naturaleza que la de 1637, usándose dicha etiqueta a modo de simplificación, en lugar de citar todos los tipos de piezas que contuvieron. Así, por ejemplo, en el siglo xIX, Ramón de Mesonero Romanos, en El antiguo Madrid (1861), daría cuenta de la fiesta como sigue: «Los días siguientes, desde el 15 hasta el 25 de febrero, continuaron las fiestas, dirigidas, el primer día, por la condesa de Olivares con teatro, baile, loas y merienda; el segundo, por el conde-duque, con máscaras, folla y entremeses» (1861: 375).

Parece que, como parte de estos entretenimientos, se hizo otra folla el 24 de febrero a cargo de la compañía de Tomás Fernández, sin especificar el lugar dentro del Buen Retiro. No obstante, de ella solo informa Cruzada Villaamil (1871c: 124), y no así las citadas fuentes.

$9 \quad$ Una de ellas parece haber sido la de Pedro de la Rosa, pues a su autor se le abonaron 1.000 reales el 3 de marzo de ese año por cinco comedias, una en el Pardo y el resto en el Retiro, correspondiendo un pago a una folla de entremeses para el martes de carnestolendas (Cruzada Villaamil, 1871c: 123-124). 
Fernández de Cabredo fue un famoso autor de comedias y gracioso. Desde 1607 dio numerosas representaciones con su compañía en Sevilla y Madrid, incluyendo autos sacramentales. Consta que en 1625 comenzó a actuar privadamente para el rey, ofreciéndole en 1634 cuatro comedias, y en 1637 nada menos que diecisiete, entre las que se contaría la folla citada (Rennert, 1909: 471-472).

Hasta 1653 no se tiene noticia de la representación de otra folla. Esta vez parece haber asumido la forma de un intermedio, concretamente, de lo que aquí se llama «sainete». En efecto, una «discreta folla» ocupó el primer intermedio de la obra Andrómeda y Perseo de Calderón de la Barca, representada en el coliseo del Real Palacio de Buen Retiro por orden de la infanta de Castilla y en celebración del cumpleaños de la reina Mariana de Austria, el 18 de mayo de 1653.

Antes de la segunda jornada, una acotación señala: «Acabó la primera jornada el admirable deleitoso susto de la caída de La Discordia. Y habiendo respirado el auditorio, divertido en un ingenioso sainete (que fue discreta folla de músicas, bailes y disfraces), empezó la segunda, transformándose la escena en una horrorosa gruta de Morfeo [...]». Como puede comprobarse, no parece denominarse aquí como «folla» a un espectáculo que reunía entremeses, sino a un sainete que era llamado así por recopilar músicas y bailes (con los intérpretes disfrazados). De modo que podría plantearse como hipótesis que lo definitorio de la folla en el siglo XVII no solo fuera el aglutinar entremeses, sino de manera genérica el reunir piezas variadas.

\subsection{Un PANORAMA SESGADO, PERO SIGNIFICATIVO}

En las páginas precedentes se ha ofrecido un panorama más amplio del que se disponía hasta el momento, aunque aún con lagunas que impiden a día de hoy ofrecer un recorrido detallado por la historia de la folla en el siglo xvII y por sus orígenes en la centuria anterior. Con todo, se pueden extraer algunas conclusiones significativas - aunque no definitivas - de los datos aquí expuestos, que permiten aumentar de forma notable el conocimiento sobre las follas en el siglo XVII, espectáculo del que hasta ahora únicamente se sabía que existió, que se relacionaba con el carnaval y que habría estado compuesto de entremeses.

En primer lugar, habría que matizar estos dos últimos aspectos, bien asentados en la historiografía. Si bien es cierto que abundan las representaciones de follas en martes de carnestolendas (en 1623, 1634 y 1636), también lo es que se interpretaron otras con motivo de acontecimientos señalados como los días de la reina Isabel de Borbón (1625), la coronación de Fernando III como rey de los romanos (1637), o el cumpleaños de la reina Mariana de Austria (1653). En el caso de la única folla conocida que se hizo en una casa privada, lo que propició su representación fue la visita de un invitado (1604). 
En segunda instancia, con relación a las características de estos espectáculos, como queda dicho, no siempre parecen haberse compuesto de entremeses e, incluso, esta denominación podría referirse no puramente a entremeses, sino de forma genérica a cualquier pieza de corta duración. Lo cierto es que se ha documentado, al menos, una folla de entremeses en la que además habría habido piezas con música (1623); una folla que aparece como de «bailes y entremeses», y que, por tanto, habría contenido números musicales bailados, además de otros propiamente declamados que serían los entremeses (1625); una folla que, a modo de recopilación, reunía «habilidades, tramoyas, bailes, entremeses, y comedias de todo el año», sin duda la más llamativa, por cuanto los entremeses tan solo parecen haber constituido una parte de todas las piezas que la componían y que venían a ser «lo escogido» de las tres compañías que la interpretaban (1637); y por último, un sainete del que se decía que reunía música y bailes y que fue «discreta folla» (1653). El hecho de que a esta última pieza se la llamara así, dice mucho de lo que se entendía por folla en la época, que no parece haber sido un género dramático propiamente dicho, sino un modo de espectáculo, una alternativa a la comedia que vendría a ser un compendio de piezas más breves.

Otro aspecto importante de estas follas es que la mayor parte de ellas eran «particulares», es decir, formaban parte de funciones que ofrecían las compañías de los corrales en casas privadas o en el Alcázar ante el monarca, y por ellas se les pagaba como por cualquier otra comedia, esto es, por lo general, 200 reales. Si se tiene en cuenta que los particulares solían ser piezas que formaban parte del repertorio de las compañías, probablemente muchas de las follas documentadas fueran como la de 1637, que reunía lo escogido de las compañías, acaso las mejores piezas que habían representado en los corrales y que ofrecían por ello a los monarcas. Con todo, ya se ha apuntado la posible existencia de muchas otras follas no interpretadas por profesionales sino por aficionados, que no hubieran dejado un rastro documental como sí lo hicieron aquellas que conllevaban el pago a las compañías.

\section{BiBLIOGRAFÍA}

Alemán, Mateo (1996). Guzmán de Alfarache. Benito Brancaforte (ed.). Madrid: Akal.

Allen, John J. (1991). «Gaspar de Porres, autor de comedias». En Manuel V. Diago y Teresa Ferrer (eds.), Comedias y comediantes. Estudios sobre el teatro clásico español. Actas del Congreso Internacional sobre Teatro y Prácticas Escénicas en los siglos XVI y XVII, organizado por el Departamento de Filología Española de la Universitat de València, celebrado en la Facultat de Filologia, los días 9, 10 y 11 de mayo de 1989. València: Universitat de València.

Ascunce, Pablo (2018). Las ermitas del Buen Retiro: religión, ocio y organización del parque. Marta García Carbonero (tutora) [trabajo de fin de grado]. Madrid: Escuela Técnica Superior de Arquitectura de la Universidad Politécnica de Madrid <http://oa.upm. es/51481/1/TFG_Ascunce_Mejia_Pablo.pdf> [Consulta: 01/05/2019]. 
AsEnsio, Eugenio (1971). Itinerario del entremés: desde Lope de Rueda a Quiñones de Benavente. Madrid: Gredos.

Biblioteca de autores españoles: desde la formación del lenguaje hasta nuestros días. Obras de don Francisco de Quevedo y Villegas. Colección completa, corregida, ordenada e ilustrada por don Aureliano Fernández-Guerra y Orbe (1859). Madrid: M. Rivadeneyra.

Breve Relación de la fiesta que se hizo a sus majestades y altezas Martes de Carnestolendas en la noche en el Alcázar de Madrid en este año de 1623. Biblioteca Nacional de España, ms. 2.354, ff. 311-312.

Brown, Jonathan y J. H. Elliot (1985). Un palacio para el rey: El Buen Retiro y la corte de Felipe IV. Madrid: Revista de Occidente.

COTARElo y Mori, Emilio (1911). Colección de entremeses, loas, bailes, jácaras y mojigangas desde fines del siglo XVI a mediados del XVIII. Madrid: Bailly-Bailliére.

Covarrubias Orozco, Sebastián (1611). Tesoro de la lengua castellana o española. Madrid: Impresor del rey Luis Sánchez.

CRUZADA VillaAmil, Gregorio (1871a). «Teatro antiguo español: Datos inéditos que dan a conocer la cronología de las comedias representadas en el reinado de Felipe IV, en los Sitios Reales, en el Alcázar de Madrid, Buen Retiro y otras partes, sacados de los libros de gastos y cuadernos de nóminas de aquella época que se conservan en el Archivo del Palacio de Madrid». El averiguador: correspondencia entre curiosos, literatos, anticuarios, etc., etc., 1 de enero, pp. 7-11.

Cruzada Villaamil, Gregorio (1871b). «Teatro antiguo español: Datos inéditos que dan a conocer la cronología de las comedias representadas en el reinado de Felipe IV, en los Sitios Reales, en el Alcázar de Madrid, Buen Retiro y otras partes, sacados de los libros de gastos y cuadernos de nóminas de aquella época que se conservan en el Archivo del Palacio de Madrid». El averiguador: correspondencia entre curiosos, literatos, anticuarios, etc., etc., 1 de abril, pp. 106-108.

Cruzada VillaAmil, Gregorio (1871c). «Teatro antiguo español: Datos inéditos que dan a conocer la cronología de las comedias representadas en el reinado de Felipe IV, en los Sitios Reales, en el Alcázar de Madrid, Buen Retiro y otras partes, sacados de los libros de gastos y cuadernos de nóminas de aquella época que se conservan en el Archivo del Palacio de Madrid». El averiguador: correspondencia entre curiosos, literatos, anticuarios, etc., etc., 15 de abril, pp. 123-125.

Da sommaia, Girolamo (2012). Diario de un estudiante de Salamanca: la crónica inédita de Girolamo da Sommaia (1603-1607). George Haley (ed.). Málaga: Universidad de Málaga.

«De las fiestas que la Majestad Católica del Rey Nuestro Señor celebró en el Real Retiro a las felicísimas nuevas de la elección y coronación de Rey de Romanos en los Reyes de Hungría y Bohemia de diez días continuos, que comenzaron Domingo 16 hasta Martes 25 de Febrero» (1637). En Relación ajustada en lo posible a la verdad y repartida en dos discursos. El primero, de la entrada en estos Reinos de Madama María de Borbón, princesa de Cariñán. El segundo, de las fiestas, que se celebraron en el Real Palacio del Buen Retiro, a la elección de Rey de Romanos. Madrid: Imprenta de María de Quiñones, ff. 12r-25v. 
Díez Borque, José María (1978). Sociedad y teatro de la España de Lope de Vega. Barcelona: Bosch.

EstePA, Luis (1994). Teatro breve y de carnaval en el Madrid de los siglos XVII y XVIII. Madrid: Comunidad de Madrid / Consejería de Educación y Cultura / Centro de Estudios y Actividades Culturales.

Etiquetas de Palacio, estilo y gobierno de la Casa Real que han de observar y guardar los criados de ella en el uso y ejercicio de sus oficios, desde mayordomo mayor y criados mayores hasta los demás criados inferiores. Funciones de la misma Casa Real ordenadas año de 1562 y reformadas el de 1624 años. Biblioteca Nacional de España, ms. 8.740, sin foliar.

Flórez Asensio, María Asunción (2006). Teatro musical cortesano en Madrid durante el siglo XVII: espacios, intérpretes y obras. Madrid: Universidad Complutense de Madrid.

GonzÁlez, Gregorio (1995). El Guitón Onofre. Manuel de las Rivas (ed.). La Rioja: Gobierno de La Rioja.

Haley, George (1971). «Lope de Vega y el repertorio de Gaspar de Porras en 1604 y 1606». En A. David Kossoff y José Amor y Vázquez (coords.), Homenaje a William L. Fichter: Estudios sobre el teatro antiguo hispánico y otros ensayos. Madrid: Castalia, pp. 257-268.

Huerta Calvo, Javier (dir.) (2001). El teatro breve en el Siglo de Oro. Madrid: Ediciones Laberinto.

Memorial histórico español (1862). Madrid: Imprenta Nacional, t. XIV.

Mesonero Romanos, Ramón (1861). El antiguo Madrid: paseos histórico-anecdóticos por las calles y casas de esta villa. Madrid: Establecimiento tipográfico de don F. de P. Mellado.

RENNERT, Hugo (1909). The Spanish stage in the time of Lope de Vega. New York: Hispanic Society of America.

SÁnchez Arjona, José (1898). Noticias referentes a los anales del teatro en Sevilla desde Lope de Rueda hasta fines del siglo XVII. Sevilla: E. Rasco.

Shergold, N. D. y John. E. VAREY (1963). «Some performances of Seventeenth-Century plays». Bulletin of Hispanic Studies, XL, pp. 212-244.

Shergold, N. D. y John. E. VAREY (1982). Fuentes para la historia del teatro en España I. Representaciones palaciegas: 1603-1699. Estudio y documentos. London: Tamesis Books.

Sommer-Mathis, Andrea (2009). «“Admirables efectos de la providencia...”. Fiesta y poder con motivo de coronaciones en el Sacro Imperio Romano». Studia Historica. Historia moderna, 31, pp. 53-94.

VAREY, John E. (1971). «La creación deliberada de la confusión: estudio de una diversión de Carnestolendas de 1623». En A. David Kossoff y José Amor y Vázquez (coords.). Homenaje a William L. Fichter: Estudios sobre el teatro antiguo hispánico y otros ensayos. Madrid: Castalia, pp. 745-754.

VAREY, John E. (1984). «The audience and the play at court spectacles: the role of the King». Bulletin of Hispanic Studies, XLI, pp. 398-406.

Vélez de Guevara, Juan (1970). Los celos hacen estrellas. J. E. Varey y N. D. Shergold (eds.). London: Tamesis Books.

Recibido: $15 / 06 / 2019$

Aceptado: 29/01/2020

Edad de Oro, XXXIX (2020), pp. 191-206, ISSN: 0212-0429 - ISSNe: 2605-3314 


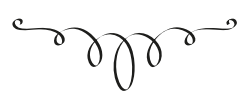

Nuevos datos acerca de las follas de entremeses del Siglo de Oro

RESUMEN: La denominada folla de entremeses es uno de los espectáculos teatrales más desconocidos del Siglo de Oro. Esto se debe en buena medida a la poca atención que le ha prestado la historiografía, y derivado de ello, a la aparente escasez de fuentes documentales que den noticia de en qué consistían y cómo, cuándo y dónde se representaban. En el presente trabajo se documentan puestas en escena de follas de entremeses hasta ahora desconocidas, que se representaron ante los monarcas en el Real Alcázar y en el Buen Retiro. Con ello se pretende un mayor conocimiento sobre este espectáculo.

PalABras Clave: folla, entremeses, bailes, teatro, Real Alcázar, Buen Retiro.

\section{New DATA ABOUt THE FOLLAS DE ENTREMESES OF DE Golden AGE}

ABSTRACT: The so-called folla de entremeses is one of the most unknown theatrical shows of the Golden Age. The bibliography on this show is scarce and there are hardly any documentary sources that explain how, when and where follas were staged. The present study offers new sources. It gives news of the stage of some follas for the monarchs in Real Alcázar and Buen Retiro. This is intended to further knowledge about this show.

Keywords: Folla, Entremeses, Dances, Theatre, Real Alcázar, Buen Retiro. 